\title{
LA DEMANDA DE EDUCACIÓN SUPERIOR EN MÉXICO 2016*
}

\author{
Nora Nidia Garro Bordonaro ${ }^{1}$
}

Armando Arcos Calzonci ${ }^{2}$

\section{Resumen}

Se analizan los aportes teóricos pioneros de Becker (1987) y algunas actualizaciones modernas (Carnoy, 2002; Llamas, 2017). Con base en esta revisión teórica se plantea la estimación de una demanda de educación superior de los hogares. El precio está representado por los ingresos laborales relativos de los trabajadores ocupados con nivel medio superior respecto de los trabajadores ocupados con nivel superior; por su parte, la cantidad demandada está representada por la proporción de estudiantes de educación superior con respecto al número de integrantes del hogar en la edad pertinente. Las variables de control seleccionadas son parte de la concepción teórica moderna del Plan de vida de los hogares, así como del conocimiento integrador requerido en el mercado laboral actual (entre otras, clima educativo, tipo de hogar, hogar urbano, preponderancia de educación pública). Se estima un modelo de demanda de educación superior, regresión lineal múltiple de corte transversal, con base en los microdatos de la Encuesta Nacional de Ingresos y Gastos de los Hogares (ENIGH 2016). Se encontró que los ingresos relativos no son estadísticamente significativos, mientras que las variables de control resultaron estadísticamente significativas. Los resultados apuntan a la conclusión de que las señales de precios o rendimientos económicos relativos no constituyen un determinante preponderante o significativo en la decisión de demandar o no educación superior por parte de los integrantes de los hogares en el rango de

1 Profesora-Investigadora, del Departamento de Economía, de la Universidad Autónoma Metropolitana, Unidad Iztapalapa.

2 Maestro en Estudios Sociales, Línea Economía Social, de la Universidad Autónoma Metropolitana, Unidad Iztapalapa.

* Fecha de recepción: 03/12/2018. Fecha de aceptación: 13/05/2019. 
edad pertinente. Por el contrario, los determinantes sociales incluidos en el Plan de Vida del Hogar (el ingreso per cápita, el clima educativo, el hogar nuclear, la preponderancia de la educación pública, el hogar dirigido por un jefe mujer, el entorno urbano) tienen relevancia a la hora de decidir la demanda por educación superior de los hogares mexicanos en el año 2016. Se propone que dicha demanda constituye un sub-plan de vida de los integrantes del hogar. Un reto teórico que se desprende de los resultados obtenidos es el contenido y medición empírica del Plan de Vida de los Hogares; a su vez, el reto de la política pública educativa es incidir en las variables incluidas pues algunas de ellas son determinantes significativos de la demanda de educación superior.

\section{Abstract}

Pioneer theoretical approach from Becker (1987) and some modern hypothesis (Carnoy, 2002; Llamas, 2017) are analyzed and used to propose the estimation of the demand of higher education of the households. The price is represented by the relative labor incomes of occupied works with high school with respect to occupied workers with higher education; in turn, the amount is measured by the proportion of students of higher education with respect to members of the household within the age of reference. The selected control variables are chosen according with the modern concepts of Plan of life of the households, as well as Integrated knowledge required in the labor market (between others, educational climate, type of household, urban household, relative importance of public education). A model of demand of higher education is estimated, on the bases of multiple linear regression with cross section data, using microdata of ENIGH 2016. The estimations show that the relative labor incomes are not statistically significant, while the other variables are. That is, the social variables included in the variable Life Plan of the Households (per cápita income, educational climate, nuclear household, public education, women head of household, urban environment) have relevance in the higher education demand of the Mexican households in the year 2016. Such demand is considered a sub-plan of the bigger one. It is a theoretical challenge to consider the variables and their empirical measurement contained in the Plan of life 
of the Households; also, the public policy challenge is to take care of these included variables because some of them are significant determinants of the higher education demand.

Palabras claves: Plan de vida; ingresos laborales relativos; clima educativo; ingresos per cápita del hogar; educación pública; el sistema hogares.

Key words: Plan of life; relative labor income; educational climate; household per capita income; public education; the homes system.

\section{Introducción}

Esta investigación tiene dos principales objetivos. El primero es presentar una discusión actualizada de las hipótesis vertidas por la teoría económica respecto a la demanda de educación, con énfasis en la educación superior. La unidad de análisis del consumidor es el hogar, considerado como un sistema que influye significativamente en la decisión de demandar educación superior por parte de sus integrantes. De esta revisión teórica surgen los principales determinantes de dicha demanda, los que guiarán la metodología de investigación empírica. Se propone el concepto Plan de Vida del Hogar, el cual incluye variables sociales y económicas -tales como el ingreso per cápita, el clima educativo, el hogar nuclear, la preponderancia de la educación pública, el hogar dirigido por un jefe mujer, el entorno urbano, entre otras-, y, además, se supone que influye significativamente en la demanda de educación superior de los hogares.

El segundo objetivo se relaciona con la propuesta de un modelo econométrico acorde con la discusión teórica anterior y los datos disponibles. Así, se pone a prueba la significancia estadística de algunos determinantes del Plan de Vida del Hogar; adicionalmente, se compara dicha significancia con la correspondiente significancia de los ingresos relativos observados en el mercado laboral. Se espera que estos últimos tengan una menor influencia que el Plan de Vida del Hogar en la demanda de educación superior. Los micro-datos utilizados para medir las 
variables propuestas están incluidos en la Encuesta Nacional de Ingreso y Gasto de los Hogares (ENIGH) en México 2016.

El contenido de este artículo incluye una primera sección que aborda el marco teórico relevante: la inversión en capital humano por parte de los hogares, abordada por los pioneros trabajos de Mincer (1958) y Becker (1987), a los cuales se agregan desarrollos metodológicos recientes, Carnoy (2000) y Llamas (2017). Se analiza el hogar actual como sistema y su relación con los sistemas educativo y laboral; y se introduce el concepto de Plan de Vida del Hogar y el sub-plan Educativo. Asimismo, se discute la medición del precio y la cantidad de demanda de educación superior. En una segunda sección se aborda la especificación de un modelo econométrico de la demanda por educación superior; las variables en los hogares mexicanos se midieron con los micro-datos de la Encuesta Nacional de Ingresos y Gastos de los Hogares (ENIGH 2016). En una tercera sección se presentan los resultados obtenidos y en una cuarta sección, las principales conclusiones. Destaca en las conclusiones la influencia estadística no significativa de los ingresos relativos observados en el mercado laboral y, por el contrario, la influencia significativa de las variables económicas y sociales incluidas en el concepto Plan de Vida del Hogar. Una tarea que surge de estos resultados es la necesidad de profundizar en el concepto del plan de vida de los hogares mexicanos, así como en su medición empírica. Esta variable resulta significativa en la determinación de la demanda de educación superior y debe ser tomada en cuenta en las políticas públicas educativas de educación superior.

\section{Marco teórico}

\subsection{Hogar y la inversión en capital humano}

Becker (1987) puso su atención en la teoría económica convencional de la explicación de las demandas de bienes y servicios por parte de los consumidores individuales, por la cual se considera que los individuos gastan un ingreso dado para maximizar su utilidad, consumiendo bienes y servicios comprados en el mercado. La condición de equilibrio en las 
demandas de estos bienes y servicios es que la relación entre utilidad marginal y precio, sea la misma para cada bien o servicio considerado. Un resultado importante de esta condición de equilibrio es que la cantidad demandada está relacionada negativamente con su precio o la ley de la pendiente negativa de la curva de demanda.

El autor consideró la extensión del análisis anterior. Por un lado, cambió la unidad de análisis del individuo considerando al hogar como el agente social primario de toma de decisiones de demanda. Por otro lado, planteó el consumo de bienes y servicios obtenidos no solamente en el mercado sino también en el ámbito privado del hogar.

Con esta extensión, el consumidor individual de la teoría convencional podría tomarse como el caso particular de un hogar con un solo miembro, concentrado en los efectos del cambio de ingresos y precios de mercado en la asignación de ese ingreso entre bienes de mercado.

El cambio de unidad de análisis permite a Becker (1987) el planteamiento de que un hogar maximiza la utilidad en el consumo de bienes y servicios adquiridos tanto en el mercado como en la producción de los mismos dentro del hogar. Las restricciones serán ahora el ingreso monetario del hogar, el tiempo dedicado al trabajo en el mercado laboral y el tiempo dedicado a la producción de bienes y servicios en el hogar.

Tómese en cuenta que la definición de bienes y servicios se amplía por la inclusión de bienes y servicios dentro del hogar, tales como auto-respeto, concepción de hijos, prestigio social, salud, altruismo, envidia y otros bienes y servicios subjetivos (Bowles y Gintis, 2011). También, se plantea la posibilidad de que un cambio en el ingreso modifique la distribución del tiempo dedicado al mercado laboral y a las actividades del hogar; por ejemplo, un aumento en los ingresos puede ocasionar mayor cantidad demandada de bienes y servicios en el mercado y menor tiempo dedicado a la crianza.

A partir de estos planteamientos, Becker (1987) se dedica a analizar las decisiones de los hogares respecto a cuáles integrantes dedicarán más tiempo al trabajo en el mercado laboral o al trabajo dentro del ho- 
gar. Se supone que los integrantes del hogar son idénticos y que las diferencias en la eficiencia o productividad no están determinadas biológicamente, sino por la experiencia e inversiones en capital humano adquiridos a lo largo de la vida. El autor señala que hay ventajas comparativas entre los integrantes del hogar y es esta ventaja comparativa la que se toma en cuenta para decidir el papel que desempeña cada uno de los miembros del hogar. Tal como sucede en el uso eficiente de los factores de la producción en una empresa, la ventaja comparativa se mide con el cociente de la relación entre las productividades marginales en el mercado y en el hogar entre los miembros del hogar.

Los integrantes del hogar buscan la maximización de la producción en el mismo. Esta maximización se logra cuando el producto marginal de tiempo dedicado al hogar con respecto al del tiempo dedicado al mercado son iguales para los individuos que se dedican a ambas actividades. El producto marginal del tiempo dedicado al hogar debe ser mayor al producto marginal del tiempo dedicado al mercado para los individuos que se dedican a las actividades hogareñas, mientras que los individuos que se dedican a actividades de mercado obtienen un producto marginal mayor en actividades de mercado que en actividades domésticas.

Con la asignación de actividades de los miembros del hogar a una actividad de mercado o doméstica (división del trabajo dentro del hogar) se entiende también cuál es el incentivo de cada integrante para realizar inversiones de capital humano en tal actividad en la cual están especializados.

Es importante señalar que la asignación de trabajo dentro del hogar también depende de otros factores distintos a la ventaja comparativa. Becker (1987) discutió el papel del sexo, del tipo de hogar, de cuestiones biológicas y culturales, y la introducción del altruismo en estas decisiones de asignación del tiempo e ingreso entre los integrantes del hogar. Estos factores fueron extensamente abordados por el autor tanto a nivel teórico como a nivel periodístico y de difusión.

Entre las decisiones económicas del hogar se encuentra la demanda de educación y la distribución eficiente de ese bien entre los miembros. Becker (1994) abordó esta cuestión siguiendo el marco de ideas anterior- 
mente expuesto, introduciendo el concepto de capital humano en el cual incluye las habilidades innatas, la educación formal e informal, la capacitación en el trabajo formal e informal, la salud, entre las principales formas $^{3}$. Al igual que todas las otras formas de capital humano, la educación se considera un bien de inversión que aumenta la productividad potencial del individuo, tanto para actividades económicas, sociales y en el hogar. Como consecuencia, esta mayor productividad explicaría las diferencias en ingresos laborales a favor de los individuos más educados.

En la Gráfica 1 se muestra, en el eje horizontal, el monto invertido (en pesos) en la inversión en capital humano (alternativamente, en el caso de la educación formal, esta inversión se mide con el número de años u otra unidad de tiempo invertido ${ }^{4}$ ). En el eje vertical, se presenta una tasa: de

3 El capital humano está incorporado en las personas y no puede ser ofrecido como garantía para su financiamiento, tal y como ocurre con el capital físico. Existe también la imposibilidad de asegurar que el capital humano pueda desarrollar su potencial productivo para el pleno desarrollo de las capacidades adquiridas. Por otro lado, Daniele Checchi (2005) afirma que quien posee capital físico se llama capitalista, mientras que el poseedor de capital humano es, en su mayoría, un trabajador dependiente: "El propietario del capital físico puede ser propiamente denominado capitalista, ya que él o ella tiene el control de emplearlo en un proceso de producción o convertirlo en un activo líquido, viviendo de él como un rentista. Por el contrario, una persona educada que posee su propio capital humano no puede emplearlo en un proceso de producción a menos que sea contratado como trabajador dependiente. Así, el capital humano no tiene el mismo poder de mercado que el capital físico". (Checchi, 2005:20)

4 El costo del tiempo invertido en la inversión en capital humano se mide por las ganancias no percibidas o comúnmente llamado costo de oportunidad en el ámbito económico. De hecho, la inversión en educación y formación se mide en tiempo, en años de escolaridad, capacitación, formación. Como la vida es finita, las inversiones anteriores proveen mayores beneficios totales en comparación con las inversiones posteriores. Una consideración adicional e importante es que como no existe persona que pueda dejar de lado su capital humano cuando realiza cualquier actividad, este capital humano entra como aportación junto con su tiempo a la producción de nuevo capital humano. El tiempo tiene poco valor para el capital humano en las primeras etapas de vida de las personas, debido a que se debe invertir recursos en los infantes, puede ser considerado hasta negativo, pero a medida que crecen las personas y se invierte en ellos mismos capital humano, consecuentemente, el valor del capital humano acumulado aumenta junto con el tiempo personal. El consiguiente aumento en el valor del 
beneficio marginal o rendimiento (para la curva de demanda del capital humano); del costo de financiación marginal o tasa de interés (para la curva de oferta de fondos de inversión del capital humano).

\section{Gráfica 1. Curvas de Oferta y Demanda por Capital Humano Capital Humano invertido (pesos)}

\section{Tasa marginal de rendimiento o costo de oportunidad}

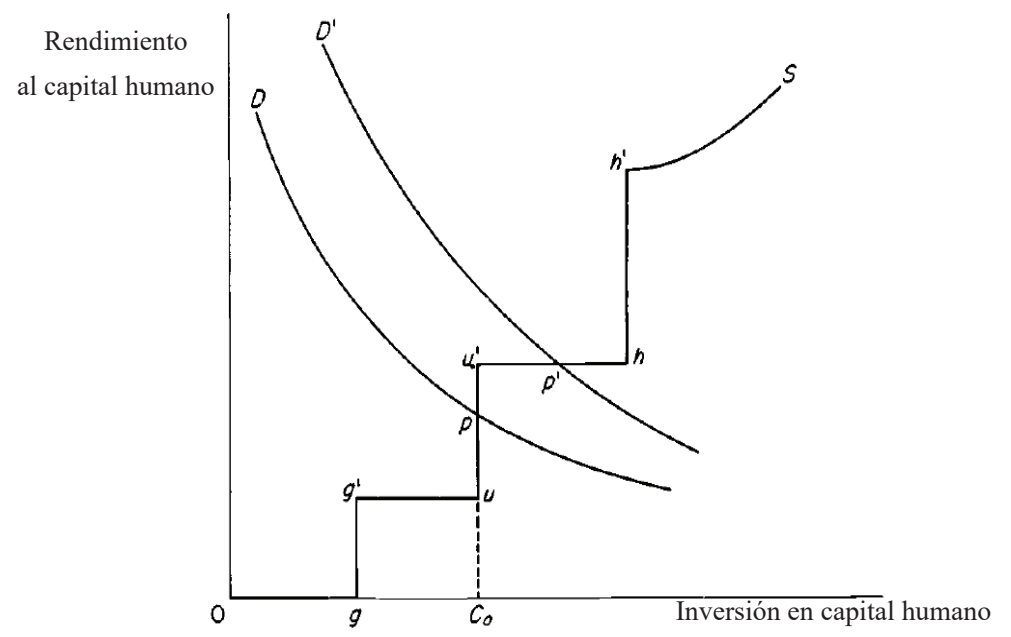

Fuente: Becker G. S., 1994, p. 112.

Por su parte, Mincer (1958) aportó la metodología empírica de medición de los rendimientos de la inversión en educación, tomando en cuenta los flujos de costos y beneficios, directos e indirectos, devengados y no devengados, privados y sociales, en el tiempo. El autor propone una medición aproximada de estos rendimientos utilizando la función semilogarítmica de ingresos laborales - posteriormente aplicada a otras formas de capital humano, como capacitación en el trabajo, experiencia laboral, salud. Por lo general, esta medición no incluye los costos financieros directos (colegiatura y gastos de mantenimiento) e indirectos de

tiempo aumenta también el costo marginal de adquirir más capital humano en periodos posteriores, ya que las inversiones posteriores usan tiempo más caro, junto con el aumento del valor del tiempo, la productividad de este sigue similar dirección, ya que la adquisición de nuevo capital humano se sirve de las inversiones acumuladas. 
la inversión (ingresos no devengados durante el tiempo de inversión) en educación formal y se enfoca en los diferenciales de ingreso laboral debido al aumento en los años de escolaridad de los trabajadores ocupados. Asimismo, los beneficios sociales de la educación formal son objeto de estudios en las ciencias sociales y la enumeración está lejos de ser exhaustiva (aumento en la participación ciudadana, mejoría en la crianza; en el comportamiento civilizado, en la comunicación social; disminución de la violencia, etc.). Por lo general, estos beneficios presentan un reto a la medición cuantitativa de los mismos ${ }^{5}$.

La curva de oferta propuesta por Becker (1994) representa la tasa de interés o costo marginal de financiación de la inversión en capital humano (ver Gráfica 1). Tal como la concibe su autor, presenta una segmentación debida a la existencia de subsidios. El comportamiento anterior da la inclinación positiva a la curva de oferta, a medida que se pasa de fuentes menos a más costosas; la tasa de aumento para cada segmento de la curva crece a medida que aumenta la segmentación en el mercado debido a la limitación de las fuentes de acceso y a la diversidad de $\operatorname{costos}^{6}$.

El ingreso se maximiza en el punto en donde se interceptan las curvas de oferta y demanda, en este caso en el monto de inversión $\mathrm{C}_{0}$ (ver

5 Por ejemplo, se podrían medir aproximadamente con los ingresos laborales antes de impuestos, bajo el supuesto de que los impuestos pagados por las personas educadas son recursos aportados al estado para los fines enunciados.

6 Las fuentes más baratas son proporcionadas por parte de padres, familiares, gobierno u organizaciones (en la Gráfica 1, los costos son nulos para los receptores de estas fuentes, segmento $0 \mathrm{~g}$ en el eje horizontal). La parte correspondiente al segmento gC0 es la fuente de financiación a bajo costo (a cargo de gobiernos o universidades, por ejemplo). A partir de cierto monto $\mathrm{C} 0$ se utilizan los recursos personales como herencias y otros obsequios monetarios directos (su costo se mide por la oportunidad perdida de utilizarlos con otros fines). Por último, los demandantes de fondos de inversión en educación pueden recurrir a préstamos comerciales en el mercado o reducir su consumo durante el periodo de inversión. Estos fondos están a disposición a un costo mayor y representan la parte correspondiente al segmento h'S de la curva de oferta. Becker (1994) explica que el CH se adquiere en periodos largos, pero en el caso de acumularse a una velocidad lenta, el costo de inversión y producción del capital disminuyen al conseguir recursos propios y reduciendo la necesidad a fuentes de financiación. 
Gráfica 1). El punto óptimo de inversión (equilibrio) se da cuando se realiza la maximización del valor actual de las ganancias, es decir, el valor presente neto de la inversión, obtenido de restar los costos realizados de los beneficios esperados ${ }^{7}$. El valor de los beneficios está determinado por el área bajo la curva de demanda, en tanto que, el valor de los costos de financiamiento se determina por el área bajo la curva de oferta. La diferencia máxima entre beneficios y costos se da en el punto donde se interceptan ambas curvas; en ese punto, los beneficios y costos de financiamiento marginales coinciden; se puede decir que la tasa de retorno (rendimiento) e interés se igualan.

\subsection{Desarrollos metodológicos recientes}

\section{El hogar actual}

El trabajo en las empresas requiere cada vez mayor flexibilidad. En la actualidad, las personas ya no requieren especializarse en tareas específicas a la manera de Adam Smith, y deben realizar en distintos momentos diversas tareas al interior del proceso productivo. Estos cambios inciden en la estructura de la familia, así como en las decisiones de educación y de trabajo (Llamas, 2017).

Carnoy (2000) investiga la relación entre mercado laboral y familia poniendo énfasis en que la relación no es unidireccional ni automática y que está permeada por variables culturales y subjetivas, las que quedan fuera de su análisis. Así, el autor se concentra en los cambios en el mercado de trabajo desde los años setenta del siglo pasado, los cuales influyen directamente sobre la estructura familiar debido a la flexibilización laboral que la globalización económica demanda. Así,

La transformación en los mercados de trabajo impone nuevas demandas a las familias. Para tener éxito en los mercados de tra-

7 El autor del modelo nos indica que durante el periodo en el que se hace la inversión, los costos de producción del capital humano se conocen antes que las ganancias y que éstas últimas representan los rendimientos totales al finalizar el periodo total de inversión. 
bajo flexibles, los trabajadores necesitan contar con amplias redes de información. Los trabajadores con más y mejor educación son más capaces de adaptarse al cambio, tienen más acceso a la información, y tienen redes más grandes y más opciones. Estas exigencias del mercado laboral flexible favorecen a los padres altamente educados y afectan tanto a los padres como a sus hijos. Las redes necesarias para que los padres sean eficaces en mercados laborales flexibles requieren una organización de decisiones más sofisticadas que en el pasado. Las familias que no tienen la capacidad de tomar decisiones informadas o los recursos para actuar sobre ellas siguen siendo forzadas a ser flexibles, pero de una manera mucho menos sostenible (Carnoy, 2000: 120).

Para el autor, los cambios en la familia vienen dados por cambios en la tecnología de producción intensivas en conocimiento, y una integración de la mujer en el mercado laboral, consolidando así nuevas formas familiares y redes sociales que ayudan a la adaptación de los núcleos familiares en la adquisición de conocimiento.

El fenómeno de cambio en las instituciones sociales debido al proceso globalizador se explica de la siguiente manera:

[...] El lugar de trabajo, la familia y la comunidad- en las que los individuos organizan sus relaciones sociales [...] están altamente interconectados y cambian simultáneamente. Ningún sitio toma la iniciativa en el proceso de cambio. La transformación en el lugar de trabajo sigue siendo crucial para el cambio en la vida de las personas [...] Sin embargo, otros cambios se originan fuera del lugar de trabajo y son tan importantes para comprender el proceso general de cambio. El rechazo de las mujeres de sus identidades asignadas por hombres como esposas y madres afecta profundamente nuestro mundo social. También interactúa con la globalización y la nueva tecnología para transformar el lugar de trabajo y la vida familiar [...] el aumento de la individualización y el aumento de los niveles de educación influyen en la identidad y la reforma de la comunidad, y éstos también interactúan con la globalización, los cambios en el trabajo y la redefinición de la 
familia para producir un conjunto aún más complejo de cambios en las relaciones sociales (Carnoy, 2000: 122).

Carnoy (2000) resalta lo que concibe como conocimiento integrador o educación amplia, necesario para integrar a las personas al nuevo entorno global (Carnoy, 2000: 123). El autor considera al estado como principal candidato de impulsar esta educación amplia.

El mercado de trabajo influye y crea también familias más flexibles, en donde el hombre ya no es el único aportador de ingresos en la familia, sino también la mujer que se ha ido incorporando con mayor impulso a la fuerza laboral. Esta flexibilización del mercado laboral trae consigo la formación de familias flexibles; por ejemplo, ha implicado cambios en sus situaciones de trabajo más a menudo que antes. Estos cambios más frecuentes de trabajo podrían significar, a su vez, una demanda de nuevas habilidades y, por lo tanto, más educación. Estos cambios afectan las demandas de educación de los jefes de familia $\mathrm{y}$, a su vez, influyen directamente sobre los requerimientos educativos mayores y mínimos que los hijos necesitan poseer.

Según el autor, la mayor flexibilidad laboral genera cambios en las expectativas de los jóvenes respecto a la formación de una familia y cambios en la estabilidad de éstas. En sus palabras: “[...] El nuevo lugar de trabajo contribuye a una mayor inestabilidad en la familia nuclear centrada en el niño, degradando la institución misma, crucial para el desarrollo económico" (Carnoy, 2000: 110).

La educación superior puede ser considerada como un medio que los hogares utilizan para adaptarse mejor a los cambios requeridos en el sistema laboral y para crear redes de las cuales se obtenga la información necesaria que la globalización acarrea. O sea, la demanda de educación superior es una opción para obtener el conocimiento integrador del que habla el autor, o también puede ser el satisfactor de conocimiento que las futuras generaciones necesitan para adaptarse a las demandas socioculturales del entorno contemporáneo. 


\section{El hogar como sistema}

El hogar puede considerarse como un sistema complejo y puede ser analizado con el enfoque de sistemas generales para su mayor comprensión. Al igual que cualquier otro sistema, el hogar es cambiante y complejo en su evolución y posee interacción continua con otros sistemas y con el medio ambiente en el que se desarrolla. Sus conexiones e interconexiones ${ }^{8}$ son influencia importante para la toma de decisiones y su evolución en el tiempo. En palabras de Lara y Llamas (2010):

El hogar [...] puede ser analizado como una unidad permeable que aprende, se modifica y adapta al medio; adquiere un conocimiento que puede ser interpretado como una estructura de conexiones, el cual tiene diferentes instancias como: la tecnología que utiliza el hogar para proveerse de recursos, las competencias o habilidades que aplican en sus actividades y los mecanismos con los que distribuye los recursos (Lara y Huitrón, 2010: 182).

En el caso de la demanda de educación superior por parte de los hogares, se supone que los miembros del hogar se educan para adquirir mayor y mejor conocimiento, mejorar la tecnología del hogar y obtener mayores recursos y mejor asignación de éstos. Una vez inmersos en el sistema laboral, los individuos tienen más posibilidades de obtener conocimiento y prácticas laborales, es decir, hay una evolución de sus ingresos y movilidad laboral. De manera esquemática (Gráfica 2) se puede ver el flujo simplificado de las conexiones entre los tres sistemas (educativo, hogar y laboral), sin que se entienda que es un proceso lineal, sino cíclico. Así, puede darse el punto de inicio desde cualquiera de estos sistemas.

8 Las conexiones son con otros sistemas como el educativo y el laboral. Las interconexiones se dan al nivel interno del hogar, es decir, las relaciones entre los integrantes del hogar. 


\section{Gráfica 2. Conexión entre sistemas: educativo, hogar y laboral}
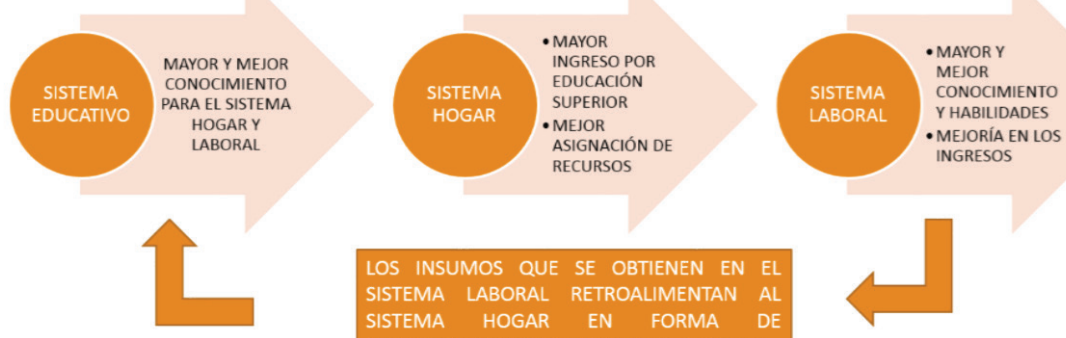

LOS INSUMOS QUE SE OBTIENEN EN EL SISTEMA LABORAL RETROALIMENTAN AL SISTEMA HOGAR EN FORMA DE CONOCIMIENTO (CAPACIDADES) E INGRESOS

Fuente: Elaboración propia con base en Lara y Llamas (2010).

El enfoque de sistemas permite analizar al hogar en, al menos, tres niveles: al interior del hogar; como un todo perteneciente a un sistema de mayor jerarquía (al sistema hogares); y en interacción con otros sistemas como el educativo y laboral.

El individuo está condicionado por lo que pasa en el sistema hogar y por tal hecho consideramos importante entender el aspecto microeconómico, el cual se puede definir como los determinantes de un plan de vida asignable a cada hogar (Gráfica 3). En esta investigación se pretende entender la dinámica microeconómica de los hogares y sus determinantes específicos en cuanto a la demanda de educación superior.

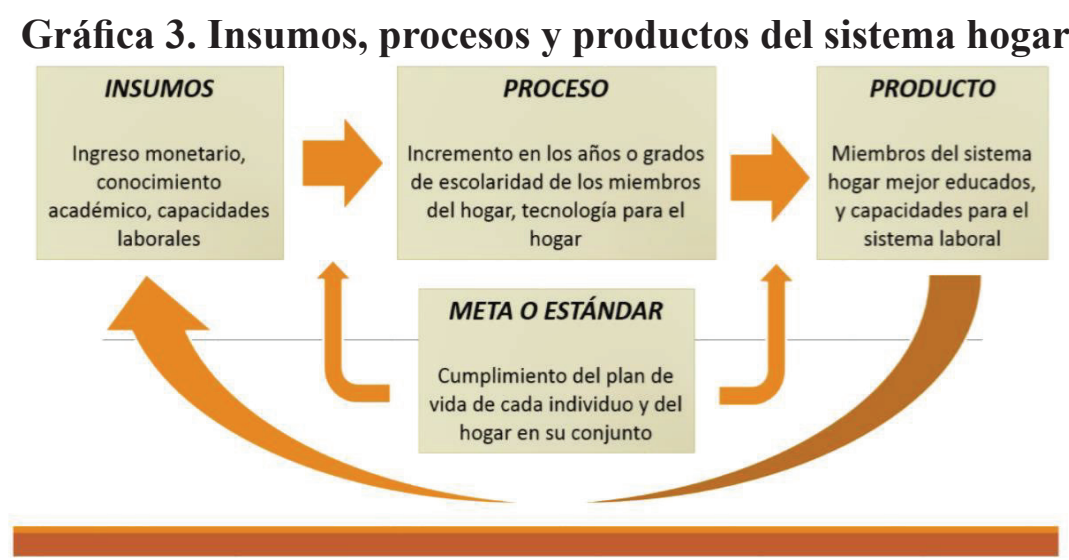

Fuente: Elaboración propia con base en Lara y Llamas (2010). 
El individuo es parte del hogar y participa del plan de vida de éste. Lo unen al hogar sentimientos subjetivos como el amor, fraternidad, solidaridad, y lealtad. Su plan de vida puede ser individual o el mismo del hogar al que pertenece, sus elecciones son de carácter racional, cultural (está influenciado y formado por el entorno y las instituciones con las que tiene interacción) y emocional (los sentimientos y la actitud hacia el riesgo son importantes al tomar decisiones) (Llamas, 2017). Por lo tanto, el individuo posee conocimiento y capacidad racional limitados para procesar la información, que adquiere a lo largo de su vida, y su aprendizaje es un proceso continuo.

Asimismo, las decisiones a las que se enfrenta el individuo pueden ser rutinarias o trascendentes, de menor a mayor nivel de importancia. Las decisiones rutinarias son de corto plazo y se tiene una experiencia previa de sus resultados; mientras que las decisiones trascendentales son de más largo plazo e influyen de manera importante en el plan de vida del individuo. Además, se toman bajo condiciones de incertidumbre. Entre las decisiones trascendentes, pueden mencionarse la decisión de hasta qué nivel educativo estudiar, si entrar al mercado laboral o seguir educándose, formar un hogar, cuántos hijos tener, elegir entre un trabajo formal o informal, cómo y en qué invertir los recursos disponibles (Llamas, 2017).

Este enfoque permite abordar el proceso de obtener insumos (información, conocimiento académico, ingresos monetarios y capacidades laborales) para la toma decisiones que logren la sobrevivencia y desarrollo del plan de vida de cada uno de sus integrantes. De forma esquemática (Gráfica 3) podemos ver el flujo simplificado de insumos, procesos internos y productos de retroalimentación al sistema hogar.

En la Gráfica 4 se distingue entre niveles de análisis micro, meso y macro. Para indagar el segundo nivel de estudio (meso) es importante integrar al hogar dentro de un sistema o taxonomía mayor, el de hogares representativos del contexto sociodemográfico (por ejemplo, tipo de hogares nucleares, ampliados, no ortodoxos, urbano-rurales), que arrojen indicios de las diferentes estructuras actuales de hogares y su influencia en la demanda de educación superior. 


\section{Gráfica 4. El sistema hogares y su interacción con otros sistemas de menor y mayor nivel de jerarquía}
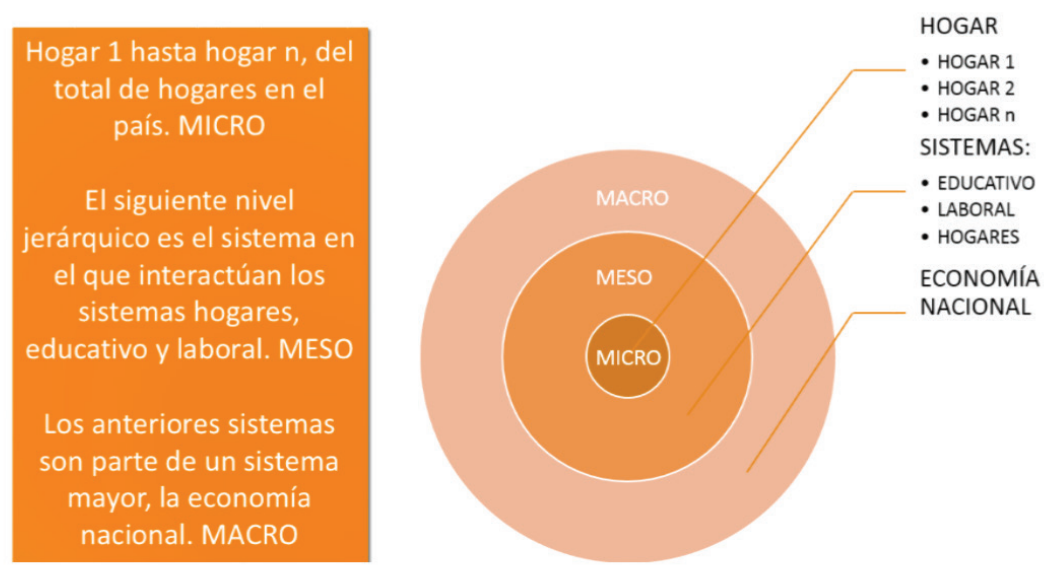

Fuente: Elaboración propia con base en Lara y Llamas (2010).

El tercer nivel de análisis (macro) hace posible el conocimiento de la interacción del sistema hogares con otros sistemas; por ejemplo, con el sistema laboral, el educativo, el financiero, el estado. y su influencia más cercana en el comportamiento y evolución del hogar mexicano.

Cada hogar en la economía se relaciona con otros hogares y juntos conforman el sistema de mayor jerarquía: el sistema hogares, el que de manera continua interactúa con el sistema educativo, laboral y otros, al mismo nivel jerárquico. Hogar por hogar están en constante relación con estos otros sistemas a través de demandar educación superior o puestos de trabajo. A su vez, cada uno de los sistemas hogares, educativo y laboral pertenecen a un entorno territorial de la economía nacional. Lo anterior sirve como apoyo gráfico para entender los sistemas y subsistemas en el que se encuentran inmersos cada uno de los hogares mexicanos.

El nivel micro de los hogares es estudiado en esta investigación mediante las características personales y agregadas de los integrantes de hogares específicos; el nivel meso mediante el uso de tipo- 
logía de conjunto de hogares; y el tercero con su interacción con el sistema educativo y laboral, con el uso de variables tales como ingreso laboral relativo, y proporción de educación pública y privada en la república mexicana.

\section{Plan de vida}

Esta sección se refiere al plan de vida del hogar, el cual se define como el agregado de los planes de vida de cada uno de sus miembros (Rawls, 1971 y 1999; Llamas, 2014). Se supone que los integrantes del hogar son racionales y que para cumplir el plan de vida general e individual se requiere una dotación mínima (determinada socialmente) de los llamados bienes primarios (libertades, derechos, autoestima o autorespeto, e ingresos).

La elección de un plan racional se supone que toma en consideración las características relevantes de la situación del hogar y una cuidadosa consideración de las posibles consecuencias. En esta investigación nos referimos al plan de vida educativo como un subplan de vida de cada integrante del hogar; este sub-plan también puede ser un elemento de otros planes que tiene el individuo como, por ejemplo, el plan de formar una familia, en qué lugar desea vivir, qué profesión elegir, etc. El sub-plan educativo es, a su vez, un elemento del plan de vida del hogar, debido a que este plan pertenece a un solo miembro del hogar, mientras que el plan de vida del hogar se conforma por los planes de vida de sus integrantes.

El plan de mayor jerarquía en este caso es el del hogar, y de manera descendente, el plan de vida de sus integrantes contiene el plan educativo, dentro del cual está inmersa la demanda de educación superior individual. 


\section{La medición del precio y la cantidad de la curva de demanda de educación superior de los hogares}

En este apartado se presenta una propuesta de medición de las variables precio y cantidad en una curva de demanda de educación superior de los hogares ${ }^{9}$.

El precio de referencia o costo de oportunidad se medirá con datos del mercado laboral de referencia para el hogar; estos datos consisten en el ingreso laboral relativo o proporción del ingreso laboral de los egresados de educación media superior con respecto al ingreso laboral de los egresados de educación superior.

O sea,

$\frac{w_{j}}{w_{i}}=\frac{\text { Ingreso laboral medio de trabajadores con educación } M S}{\text { Ingreso laboral medio de los trabajadores con ES }}$

donde $\mathrm{w}=$ ingreso laboral promedio, $\mathrm{j}=$ educación media superior (MS) e $\mathrm{i}=$ educación media superior (ES).

Esta proporción es una medición del costo de oportunidad de adquirir educación superior o bien del precio que se está dispuesto a pagar para recibirla: a menor precio aumentará la cantidad demandada y viceversa ocurrirá a mayores precios.

Por su parte, la cantidad demandada consistirá en una proporción de integrantes del hogar entre 17 y 25 años inscritos en educación superior con respecto a los integrantes del hogar con educación media superior en el mismo rango de edad.

O sea,

$$
\frac{N_{i}}{N_{j}}=\frac{\text { Miembros del hogar inscritos en ES del grupo etarario }}{\text { Miembros del hogar con educación MS del grupo etario }}
$$

Donde $N i$ es el número de miembros del hogar inscritos en una institución educativa del nivel medio superior, de 17 a 25 años; y $\mathrm{Nj}$ el

9 Las mediciones propuestas están basadas en la metodología utilizada por Acemoglu (2002) y Johnson (1997) para medir el efecto del cambio tecnológico en la demanda de trabajo. 
correspondiente número de miembros con educación superior, de la misma edad. La Gráfica 5 ilustra la función de demanda propuesta.

\section{Gráfica 5. Oferta y Demanda de educación superior}

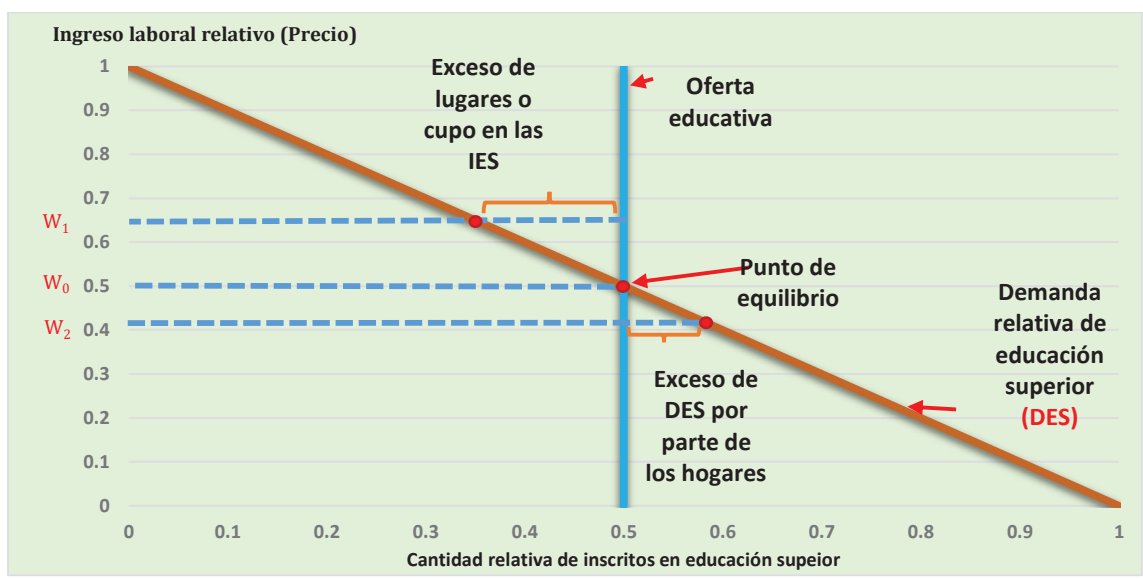

Fuente: elaboración propia con base en Llamas (2010).

La construcción de estos índices de precio y cantidad facilita la estimación de la función de demanda y los movimientos sobre dicha función, así como los desplazamientos de ésta generados por otras variables explicativas de interés. Tómese en cuenta que la función de demanda discutida es la de un hogar; por lo tanto, en un tiempo dado, existe una demanda total de educación superior que sería la sumatoria horizontal de las proporciones $\mathrm{Ni} / \mathrm{Nj}$ de cada hogar al nivel $\mathrm{Wj} / \mathrm{Wi}$ establecido en el mercado laboral.

Para los propósitos de esta investigación, se puede considerar la oferta de educación superior, en un tiempo dado, como una proporción fija entre el cupo de inscritos en el nivel educativo superior con respecto al número de egresados de la educación media superior, en el rango 17 a 25 años. Pero se puede adelantar, como ejemplo, que si consideramos el costo de oportunidad $\mathrm{Wj} / \mathrm{Wi}$ propuesto como uno de los determinantes relevantes de tal oferta; entonces, una disminución de esta proporción sería una señal del mercado laboral de aumento en los ingresos de los egresados de educación superior con respecto a los egresados de educa- 
ción media superior. Señal captada por los hogares, los cuales exigirán un aumento en el cupo de estudiantes aceptados en el ciclo superior, o bien será una política educativa congruente del estado con las exigencias del mercado laboral. De allí que en la Gráfica 5, la oferta de educación media sería inelástica en un tiempo dado y se desplazaría a la derecha si el mercado laboral y los hogares $-\mathrm{u}$ otras consideracionesasí lo requieran. Por el contrario, y como otro ejemplo, si en un tiempo dado aumenta el índice Wj/Wi ello indicaría que el costo de oportunidad de la educación superior crece, con lo cual los hogares -al menos los hogares del país en cuestión- requerirían menos cupo en las instituciones de educación superior.

Por supuesto, el mercado laboral y los ingresos laborales relativos pueden no ser los principales determinantes de la oferta de educación superior a cargo de instituciones públicas o privadas, puesto que la educación superior tiene también otros fines económicos, sociales y culturales no asociados necesariamente con los ingresos relativos futuros (por ejemplo: tipo de hogar, nivel de ocupación laboral del hogar, clima educativo del hogar, número de hijos dependientes del hogar, condición de hogar urbano, preponderancia de estudiantes en instituciones de educación pública en el hogar, ingreso per cápita del hogar, disponibilidad de becas educativas en el hogar, etc.). Estas otras variables (denominadas variables de control) establecen la posición de la demanda de educación superior, la cual cambia al variar dichas variables. Por ejemplo, si ha aumentado el ingreso per cápita de los hogares, es de esperar un desplazamiento en la curva de demanda de educación superior; asimismo, un aumento en el clima educativo, en la forma de máxima escolaridad alcanzada en un hogar, también es probable que desplace la curva de demanda de educación superior de los hogares. La dirección de tales desplazamientos es una cuestión de hipótesis teóricas y de comprobación empírica.

\section{Modelo econométrico}

La especificación del modelo de regresión estimado en esta investigación es la siguiente: 


$$
\begin{aligned}
& D E S i=\beta 0+\beta 1(I L R i)+\beta 2(I P C H i)+\beta 3\left(C L I M \_E D U i\right)+\beta 4\left(C L A S E \_H O G i\right)+ \\
& \beta 5\left(O C U_{-} H O G i\right)+\beta 6(R U R-U R B i)+\beta 7(B E i)+\beta 8(P E P U B i)+\beta 9(S E X J E F i)+u i
\end{aligned}
$$

donde:

$$
\begin{aligned}
& \text { DESi = Demanda relativa de educación superior en el hogar } \\
& \text { ILRi = Ingreso laboral relativo de los hogares por cada entidad federativa } \\
& \text { IPCHi = Ingreso per capita del hogar } \\
& \text { CLIM_EDUi = Clima educativo del hogar } \\
& \text { CLASE_HOGi = Clase de hogar } \\
& \text { OCU_HOGi = Proporción de ocupados en el hogar } \\
& R U R-U R B i=\text { Hogar rural - urbano } \\
& \text { BE }=\text { Beca educativa en el hogar } \\
& \text { PEPUBi = Preponderancia de educación pública en el hogar } \\
& \text { SEX_JEFi = Sexo del jefe del hogar } \\
& U_{i}=\text { residuos no explicados. }
\end{aligned}
$$

La variable dependiente es la demanda de educación superior del hogar (DES). Como se dijo en la Sección anterior, su medición es la siguiente proporción:

$$
D E S=\frac{N_{i}}{N_{j}}=\frac{\text { Miembros del hogar inscritos en ES del grupo etarario }}{\text { Miembros del hogar con educación MS del grupo etario }}
$$

Las variables independientes son las siguientes ${ }^{10}$ :

(ILRi) es el ingreso laboral relativo. Como se dijo en la Sección anterior, su medición es la siguiente proporción:

$$
\mathrm{ILRi}=\frac{w_{j}}{w_{i}}=\frac{\text { Ingreso laboral medio de trabajadores con educación } M S}{\text { Ingreso laboral medio de los trabajadores con ES }}
$$

10 La especificación de las variables explicativas y su posible efecto sobre la variable a explicar son propuestos con base en la Sección I de esta investigación y la revisión de investigaciones teóricas y empíricas citadas en el Anexo 1. Con respecto a la variable Plan de vida de los hogares (ver Sección I.2) se propone el siguiente índice que estimaría las expectativas de los hogares respecto a la demanda de educación superior de los integrantes. Cabe destacar que este índice no se incluyó en las variables explicativas porque presentaría un grado elevado de multicolinealidad con las variables incluidas en el modelo, debido a que éstas forman parte del plan de vida de los hogares (ingreso per cápita, clima educativo, nivel de ocupación, preponderancia de educación pública, beca educativa para algún integrante del hogar, condición urbano-rural del hogar, clase de hogar). 
Cabe señalar que en la medición de este índice se consideraron los ingresos laborales promedios de trabajadores ocupados con educación media superior y superior del estado federativo donde se sitúa el hogar encuestado. Como se explicó en la Sección anterior, se espera encontrar una relación negativa entre esta variable y demanda de educación superior.

(IPCHi) es el ingreso per-cápita del hogar. Se espera encontrar una relación positiva respecto a la demanda de educación superior. $\mathrm{O}$ sea, se espera que la educación superior sea un bien económico normal.

(CLIMA_EDUi) es el clima educativo, medido como la escolaridad máxima lograda en el hogar. Se espera encontrar una relación positiva entre esta variable y la demanda de educación superior, debido al efecto demostración.

(CLASE_HOGi) consiste en una variable binaria con valor unitario en el hogar no nuclear. Las clases de hogar utilizada en la ENIGH 2016 consta de cinco categorías: unipersonal, nuclear, ampliado, compuesto y corresidente. Se tomó como grupo base a los hogares nucleares por ser los más numerosos (64\%) y que consisten en padre, madre e hijos. Se espera que si el hogar es nuclear exista una relación positiva respecto a la demanda de educación superior. Esto debido, según las teorías convencionales del hogar, a una mayor cohesión y apoyo económico entre los integrantes, fraternidad y sentimientos como el altruismo y el amor entre padres

Variable Plan de vida educativo (PVE): Esta variable podría cuantificarse con un índice de la "expectativa" del hogar respecto a la máxima educación esperada de acuerdo con el clima educativo actual. Dicho clima estará indicado por la máxima escolaridad actualmente alcanzada por algún miembro del hogar. La variable Plan de vida sería entonces una "expectativa" que los miembros del hogar entre 17 y 25 años tienen, de acuerdo con el clima educativo del hogar al que pertenecen; su medición requiere partir de la unidad (representativa del clima educativo observado) y adicionar una fracción - positiva o negativa, cuestión empírica- que mediría la expectativa para el futuro de cada integrante del hogar. El interés de incluir el plan de vida educativo sería medir su efecto directo en la demanda de educación superior de los miembros del hogar. La construcción de tal índice requiere información no disponible actualmente en las grandes bases de datos del INEGI. 
e hijos, lo cual influye positivamente sobre los planes de vida de cada uno de sus miembros.

(OCU_HOGi) mide la proporción de integrantes ocupados en el hogar. Se esperan dos efectos posibles. El primero es un efecto positivo sobre la demanda de educación superior debido a que el mayor número de integrantes del hogar ocupados posiblemente aporta ingresos adicionales para apoyar las demandas de los integrantes jóvenes; el efecto negativo se espera cuando los integrantes del hogar ocupados crean expectativas de ingresos propios en los miembros más jóvenes, motivándolos a incorporarse al mercado laboral.

(RUR_URBi) es la variable que distingue si la zona donde se ubica el hogar es rural o urbana, siendo la unidad asignada a los hogares rurales. Se espera que exista mayor demanda de educación superior en los hogares de zonas urbanas debido a la mayor oferta de educación superior en estas zonas con respecto a las rurales.

(BEi) es una variable binaria, cuyo valor unitario indica que al menos un integrante del hogar cuenta con beca escolar. Se espera una relación positiva de esta variable con la demanda de educación superior del hogar debido a que este apoyo aumenta la fuente de financiación para la educación superior.

(PEPUBi) es una variable binaria cuyo valor unitario indica un hogar con estudiantes preponderantemente (más del 50\%) en instituciones de educación pública. Se esperan dos efectos posibles de esta variable sobre la demanda de educación superior. El primero, positivo, debido a que los gastos educativos de los hogares con hijos estudiando en escuelas públicas son menores respecto a escuelas privadas, lo cual permitiría la reducción del gasto en educación y la posibilidad de asignar fondos adicionales a la demanda de educación superior. El segundo, negativo, se espera debido a que si el hogar cuenta con alta preponderancia de la educación pública indica que tentativamente sus integrantes asisten a instituciones públicas debido a sus bajos ingresos o a que encuentran restricciones adicionales para poder acceder a la educación superior. 
(SEX_JEFi) es una variable binaria del sexo del jefe del hogar, con valor unitario si el jefe es mujer. Se espera encontrar una relación positiva respecto de la demanda de educación superior cuando el jefe del hogar es mujer, de acuerdo con otros hallazgos empíricos de los hogares dirigidos por mujeres que, aunque tienen mayores restricciones económicas y sociales para cumplir su plan de vida, logran influir positivamente en la DES de sus integrantes (ver Anexo 1).

\section{Resultados}

Los microdatos utilizados consisten en la muestra de 73,311 hogares encuestados en la ENIGH 2016, la cual representa una proyección estimada de 33,462,598 hogares en México en ese año. Cabe destacar que la demanda de educación superior surge del 39\% de dichos hogares, de acuerdo con las estimaciones mostradas en la Gráfica 6 (primera sub-gráfica).

\section{Características de las variables de interés}

En las Gráficas (a-j) se presenta una descripción de la distribución de la demanda de educación superior (DES) en los hogares, desglosada por grupos de interés. Además, se presentan los ingresos laborales relativos de los trabajadores ocupados con educación media superior y superior, por entidad federativa.

\section{Gráficas 6. La demanda de educación superior (DES) en los hogares. México 2016}

a) Hogares con y sin DES

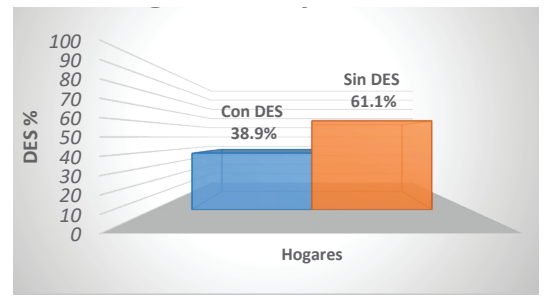

b) DES por clima educativo

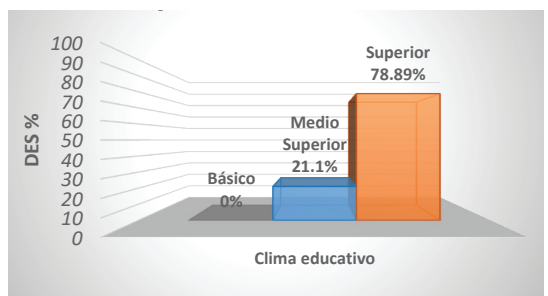


c) DES por clase de hogar

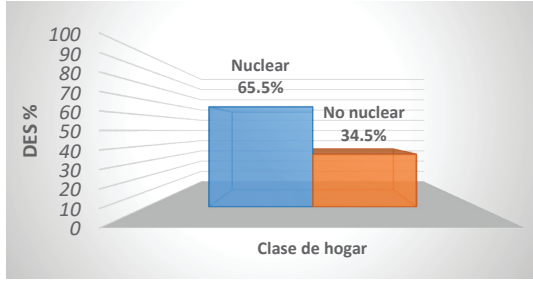

e) DES por sexo del jefe

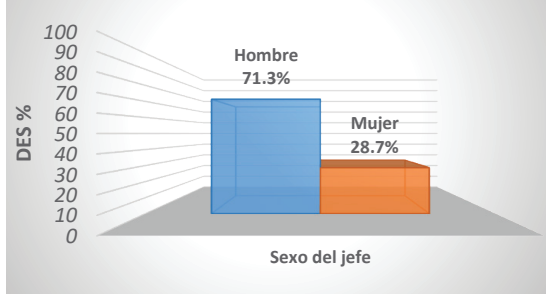

g) DES por zona urbana-rural

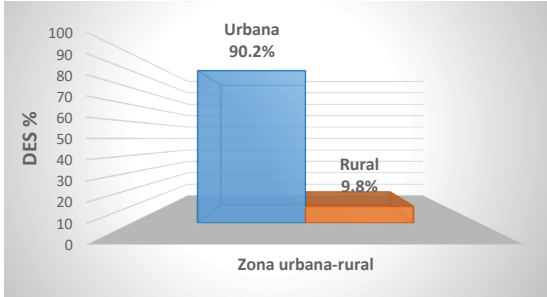

i) DES por ingreso per cápita del hogar

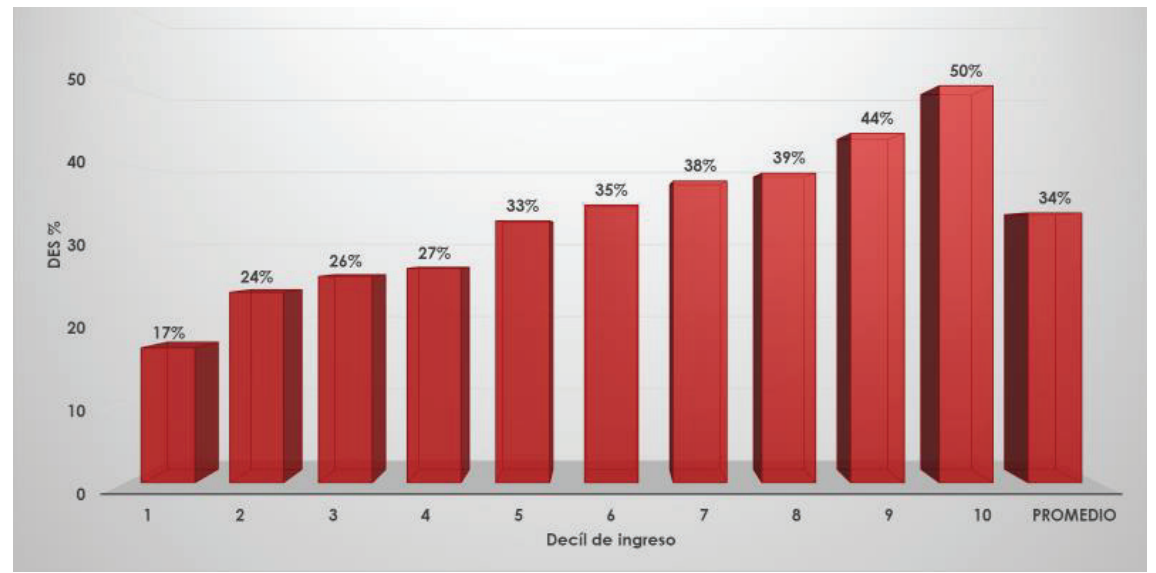

d) DES por ocupados

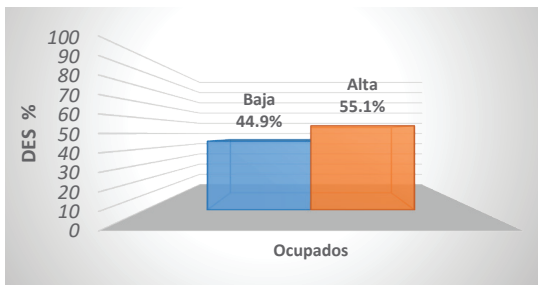

f) DES por beca educativa

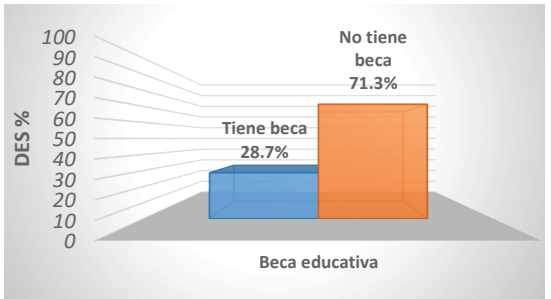

h) DES por preponderancia de educación pública

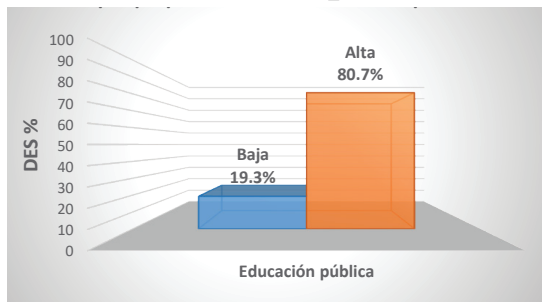

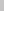




\section{j) Ingreso laboral relativo de los trabajadores ocupados con educación media superior y educación superior (ILR)}

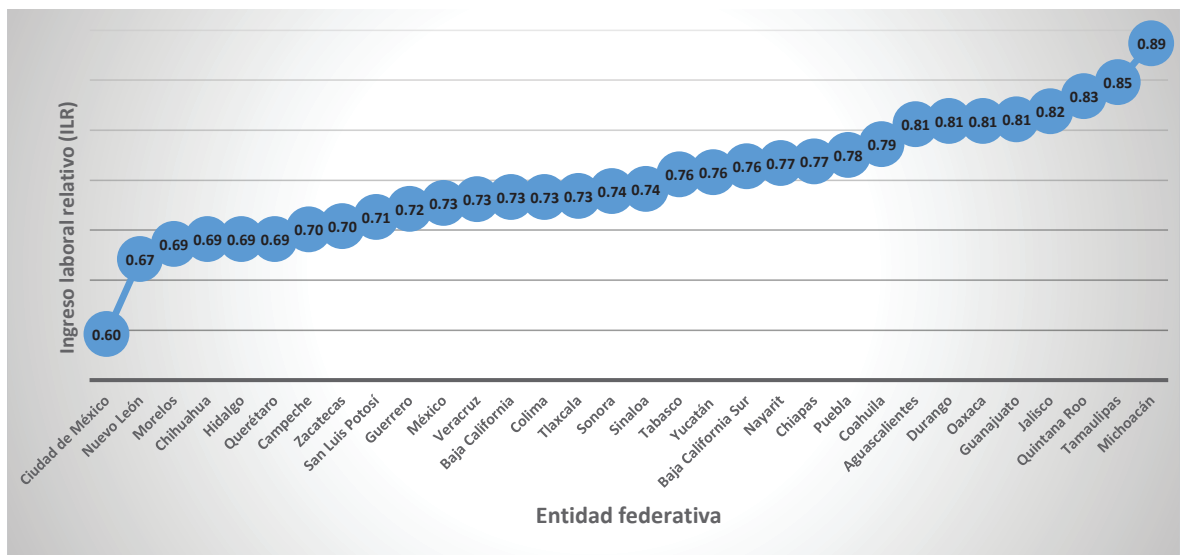

Las Gráficas 6 (a-j) muestran que la demanda de educación superior en los hogares de México 2016 está correlacionada positivamente con el clima educativo (b), el hogar nuclear (c), el nivel de ocupación (d), el jefe de hogar hombre (e), la beca educativa (f), el sector urbano (g) y la preponderancia de educación pública $(\mathrm{h})^{11}$. Además, los ingresos relativos de los trabajadores ocupados con educación media superior y educación superior por entidad federativa indican que el diferencial de ingresos es mayor en la Ciudad de México (donde el ingreso laboral por hora trabajada de los trabajadores con educación media superior es, en promedio, el 60\% del correspondiente a los trabajadores con educación superior; el menor diferencial se encuentra en el estado de Michoacán (89\%); y el diferencial promedio es del $74 \%{ }^{12}$. (Ver Gráfica $6 \mathrm{j}$ )

11 La cuestión de la significancia estadística y la jerarquización de la correlación se obtiene en la estimación del modelo de regresión, presentado a continuación.

12 Otros promedios de variables explicativas de interés son: clima educativo, 10.7 años de escolaridad; hogares nucleares, 64\%; proporción de ocupados, 0.50; hogares urbanos, 64\%; con beca educativa, 26\%; preponderancia de educación pública, 99\%; jefes de hogar mujeres, $72 \%$. 


\section{Estimaciones del modelo de regresión}

El modelo econométrico seleccionado es un modelo de regresión múltiple de corte transversal para el año 2016, de los hogares a nivel nacional que tienen una demanda de educación superior.

El Cuadro 1 muestra las estimaciones del modelo econométrico propuesto en la Sección $3^{13}$.

\section{Cuadro 1. Estimación del modelo econométrico de la Demanda de educación superior (DES) en los hogares, México 2016}

(Variables explicativas, Coeficientes de regresión y Significancia estadística)

\begin{tabular}{|l|c|c|c|}
\hline \multicolumn{1}{|c|}{ Código } & $\begin{array}{c}\text { Nombre de la } \\
\text { variable }\end{array}$ & Coeficiente & $\begin{array}{c}\text { P-Valor Significancia } \\
\text { estadística }\end{array}$ \\
\hline ILR & $\begin{array}{c}\text { Ingreso laboral } \\
\text { relativo }\end{array}$ & -0.04 & 0.529 \\
\hline IPCH & $\begin{array}{c}\text { Ingreso per-cápita } \\
\text { del hogar }\end{array}$ & 0.04 & 0.000 \\
\hline CLIM_EDU & $\begin{array}{c}\text { Clima educativo en } \\
\text { el hogar }\end{array}$ & 0.06 & 0.000 \\
\hline CLASE_HOG & Clase de hogar & -0.07 & 0.000 \\
\hline OCU_HOG & $\begin{array}{c}\text { Proporción de ocu- } \\
\text { pados en el hogar }\end{array}$ & -0.07 & 0.000 \\
\hline RUR_URB & Hogar Rural-Urbano & -0.07 & 0.000 \\
\hline BE & Beca educativa & -0.00 & 0.802 \\
\hline PEPUB & $\begin{array}{c}\text { Hogar preponde- } \\
\text { rantemente con } \\
\text { educación pública }\end{array}$ & -0.12 & 0.000 \\
\hline SEX_JEF & $\begin{array}{c}\text { Sexo del jefe del } \\
\text { hogar }\end{array}$ & 0.03 & 0.000 \\
\hline
\end{tabular}

$\mathrm{R}$ cuadrado ajustado $=0.18$.

Fuente: elaboración propia con base en micro-datos de la ENIGH 2016 y STATA 14.2.

13 Se utilizó el paquete econométrico STATA 14.2, para un modelo de corte transversal con factor de expansión de la muestra, previas pruebas para evitar problemas de sesgos en los resultados debido a la multicolinealidad entre las variables explicativas, y con transformación de variables para evitar heteroscedasticidad y/o autocorrelación de residuos utilizando el comando robust. 
El modelo planteado explica el 18\% de las variaciones en la DES de los hogares, lo cual indica la complejidad de la variable dependiente (DES), aunque la mayoría de las variables incluidas tienen un efecto estadísticamente significativo en la DES, salvo dos variables: el ingreso laboral relativo (ILR) y la presencia de alguna beca educativa en el hogar (BE), de acuerdo con el P-valor cercano a la unidad de los coeficientes de estas dos variables.

Dado que la variable ILR representa el costo alternativo de la demanda de educación superior - ver Sección I- este resultado indica que la curva de demanda de educación superior es totalmente elástica con respecto al precio o costo de oportunidad representado por los diferenciales en los ingresos futuros esperados en el mercado laboral. En otras palabras, la decisión de demandar educación superior es independiente del costo de oportunidad medido de esa manera. Más aun, esta demanda depende significativamente de las otras variables tomadas en consideración en el modelo, cuyos coeficientes resultaron estadísticamente significativos. Lo mismo sucede con la existencia o no de becas educativas en el hogar (BE).

Por lo tanto, salvo ILR y BE, las otras variables incluidas en el modelo afectan significativamente a la DES de los hogares mexicanos en el año 2016 para cualquier nivel de confianza, de acuerdo con el P-valor igual a 0.000 . Destacan los efectos positivos (es decir, contribuyen al aumento de la DES) el mayor ingreso per cápita, el clima educativo medido por la educación máxima en el hogar, la clase de hogar nuclear, la preponderancia de educación no pública, la disminución de la proporción de ocupados, el hogar urbano, la preponderancia de educación no pública, el sexo femenino del jefe de hogar. En general, estos resultados concuerdan con los esperados.

\section{Conclusiones}

En esta investigación se presenta un marco teórico y empírico de la demanda de educación superior de los hogares de México 2016. El marco teórico, parte de los planteamientos pioneros de Becker (1978 y 1994), 
los cuales se actualizan con aportes modernos a cargo de Carnoy (2000) y Llamas (2017). Estas fuentes permiten considerar la demanda de educación superior originada en el sistema de hogares a partir del plan de vida de sus miembros, alimentado a su vez con insumos (ingresos y conocimientos académicos y laborales) y produciendo, como uno de sus resultados, integrantes del hogar educados y capacitados para el mercado laboral. Estos resultados, a su vez, retroalimentan los insumos del sistema de hogares. Así, la demanda de educación de los hogares se origina a un nivel meso, en el cual se procesan o transforman los insumos del hogar y, al final del proceso, el hogar incrementará los conocimientos académicos de sus miembros, lo cual permite generar un nuevo ciclo del proceso.

A continuación, se propone una medición de la demanda de educación superior y se identifican los determinantes socioeconómicos y demográficos de la demanda de educación superior para los cuales se cuenta con mediciones empíricas para México. Así, a partir de los microdatos de la ENIGH 2016 se construyeron las siguientes variables o determinantes de la demanda de educación superior: ingreso laboral relativo de los trabajadores con educación superior, ingreso per cápita del hogar, clima educativo, tipo de hogar, nivel de ocupación, sexo del jefe de hogar, hogar rural-urbano, preponderancia de educación pública y becas de estudio.

Las estimaciones econométricas mostraron que los ingresos laborales relativos entre los trabajadores ocupados con nivel de educación media superior y superior (ILR en esta investigación) no influyen significativamente en la demanda de educación superior. Tampoco influye, en la decisión de demanda de educación superior, la existencia de al menos una beca de estudios en el hogar. Por el contrario, influyen positivamente en la demanda de educación superior el resto de las variables explicativas incluidas en el modelo. En primer lugar, la preponderancia de educación pública; en segundo lugar, el hogar urbano, el hogar nuclear y el nivel de ocupación del hogar; en tercer lugar, el clima educativo; en cuarto lugar, el ingreso per cápita del hogar y, en quinto lugar, la presencia de jefa de hogar. Estos resultados son, en general, los es- 
perados de acuerdo con la bibliografía consultada en el marco teórico y las estimaciones empíricas recientes (ver Anexo 1).

Estos resultados apuntan a la conclusión de que las señales de precios o rendimientos económicos relativos no constituyen un determinante preponderante o significativo en la decisión de demandar o no educación superior por parte de los integrantes de los hogares en el rango de edad pertinente. Por el contrario, los determinantes sociales (el estatus del ingreso per cápita, el clima educativo como conocimiento integrador, el hogar nuclear, la preponderancia de la educación pública, el hogar dirigido por un jefe mujer, el entorno urbano) tienen mayor relevancia a la hora de decidir la demanda por educación superior.

En términos más generales, a nivel teórico, la variable incluyente Plan de vida del hogar se presenta como una variable teórica que requiere atención en cuanto a su contenido y a su medición empírica. Las políticas públicas deben considerarla pues es un determinante empírico más relevante que los ingresos relativos en el mercado laboral cuando se trata de la demanda de educación superior. Esta demanda es un subplan educativo de los integrantes individuales del hogar, el cual se desprende o es consecuencia de un plan de vida más general.

Por último, cabe destacar que las estimaciones presentadas surgen de un análisis de corte transversal, para el año 2016. Circunstancias sociales, políticas, culturales, demográficos, nacionales y globales, por lo tanto, determinan estos resultados. Por ello, en el futuro será importante realizar un análisis considerando datos panel para detectar tendencias.

\section{Bibliografía}

Acemoglu, D. (2002), "Directed Technical Change". The Review of Economic Studies, 69, 781-809.

Acevedo, S., Zuluaga, F., \& Jaramillo, A. (2008), "Determinantes de la demanda por educación superior en Colombia", Revista de Economía del Rosario, 121-148.

Becker, G. (1987). Tratado sobre la familia. Madrid: Alianza. 
Becker, G. S. (1987). Teoría económica. México: Fondo de Cultura Económica.

Becker, G. S. (1994). Human Capital: A Theoretical and Empirical Analysis with Special Reference to Education (3rd Edition). Chicago and London: National Bureau of Economic Research.

Bowls, Samuel y Gintis, Herbert (2011). A cooperative species: human reciprocity and its evolution. Princeton University Press.

Cañabate, D. A. (1998). La demanda de educación superior en el sistema público catalán. Barcelona: Universidad Politécnica de Cataluña.

Carnoy, M. (2000). Sustaining the new economy. Work, family and Community in the Information Age. Cambridge: Harvard University Press.

Checchi, D. (2005). The economics of education. Human Capital, family background and Inequality. Cambridge: Cambridge University Press.

Cohn, E. (1990). Los beneficios de la educación. Michigan: Pergamon Press. CONEVAL. (24 de mayo de 2018). CONEVAL.

Gujarati, D., \& C. Porter, D. (2009). Econometría. México: McGraw Hill/Interamericana Editores S.A. de C.V.

Hernández Torres, M. (Julio de 2013). "Repercusiones de los estudios de maestría en la trayectoria profesional de posgraduados de la Universidad de Colima". Villa de Álvarez, Colima, México: Universidad de Colima.

Hirsch, F. (1976). Social limits to growth. Massachusetts: Twentieth Century Fund.

Ibarra Colado, E., \& Porter Galetar, L. (2007). "La evaluación como herramienta de control: lecciones mexicanas sobre las disputas con los mercaderes del templo del saber". En M. A. Navarro L., \& I. Sánchez Rodríguez, Transformación mundial de la educación superior. Puebla, México: Universidad Iberoamericana Puebla, pp. 169-222. 
Iglesias Garrido, J. (2005). Capital humano y señalización. Bellaterra, Barcelona, España: Universidad Autónoma de Barcelona.

INEGI, (2016), Encuesta Nacional de Ingresos y Gastos de los Hogares (ENIGH), México, diciembre

Jinés Mora, J. (1988). Motivaciones socioeconómicas de la demanda de educación superior. Ekonomiaz.

Johnson, G. (1997), "Changes in earnings inequality: the role of demand shifts", Journal of Economic Perspectives, vol. 11, núm. 2, primavera 1997, pp. 41-54.

Lara Caballero, M., \& Llamas Huitrón, I. (2010). "Permanencia educativa en los hogares rurales. El caso de México 2005”. En I. Llamas Huitrón, N. Garro Bordonaro, \& G. Campos Ríos, Política Social: enfoques y análisis. D.F., México: Universidad Autónoma Metropolitana, pp. 169-209.

Llamas Huitrón, I. (2017). Educación y desarrollo socioeconómico en los países en desarrollo. Borrador. Iztapalapa, Ciudad de México, México.

Llamas Huitrón, I. (2013). "Desigualdad y gasto educativo en los hogares mexicanos 1996- 2010”. En G. Félix Verduzco, \& G. Aboites Manrique, Dimensiones socioeconómicas de la pobreza en México. Saltillo, México: Plaza y Valdés S.A. de C.V., pp. 41-72.

Llamas Huitrón, I. (2014). Utilitarismo y contractualismo. Fundamentos para la evaluación de políticas públicas. Ciudad de México: Gedisa.

López Lubian, F. J. (1981). La demanda social de educación superior. Estudio de la Universidad de Barcelona. Barcelona, España.

Martínez Torres, J. A. (mayo de 2012). Factores de mediación en la posición laboral y el ingreso de los profesionistas de las áreas de ingeniería y jurídico administrativas en tres localidades de Tamaulipas. Tesis doctoral. Ciudad Victoria, Tamaulipas, México: Universidad Autónoma de Tamaulipas. 
Mincer, Jacob (1958), "Investment in human capital and personal income distribution", Journal of Political Economy, Agosto.

Mora Ruiz, J. G. (1990). La demanda de educación superior. Madrid: Consejo de universidades. Secretaría General.

Pollak, R. A. (2002). Gary Becker's contributions to family and household economics. Cambridge: National Bureau Of Economic Research.

Rawls, J. (1971). A Theory of Justice. Cambridge, MA: Harvard University Press.

(1999). A Theory of Justice. Cambridge, MA: Harvard University Press. Edición revisada.

Wooldridge, J. M. (2010). Introducción a la econometría. Un enfoque moderno. Ciudad de México: Cengage Learning Editores, S.A. de C.V.

\section{Anexo 1. Antecedentes empíricos}

Se han revisado investigaciones que examinan el fenómeno de la DES y sus implicaciones socioeconómicas en distintos países como Colombia, España y México (Jinés, 1988; Acevedo et. al., 2008; López, 1981; y Llamas 2013) (Cuadro A1). 


\begin{tabular}{|c|c|c|}
\hline 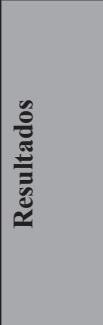 & 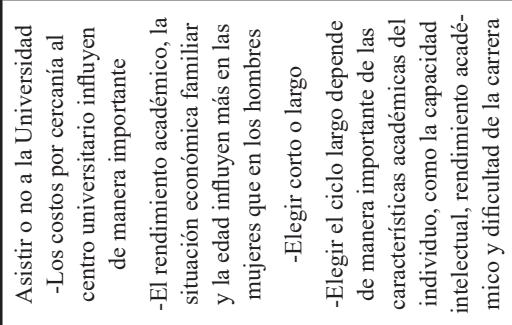 & 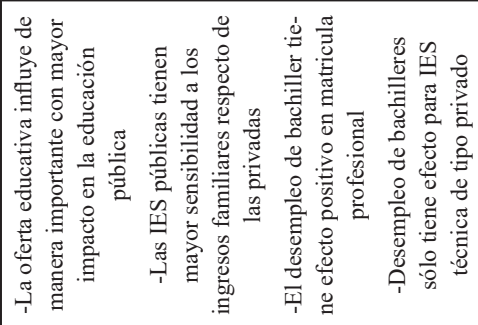 \\
\hline 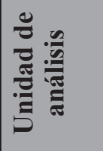 & 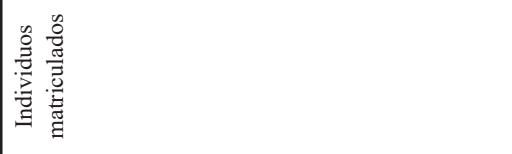 & 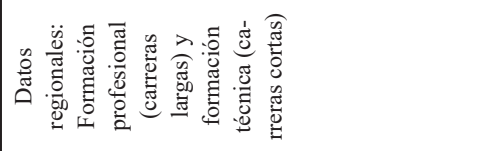 \\
\hline 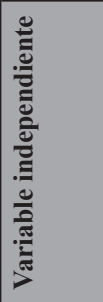 & 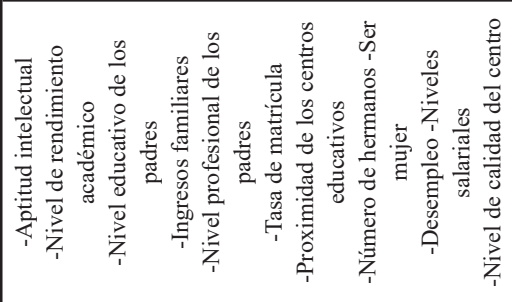 & 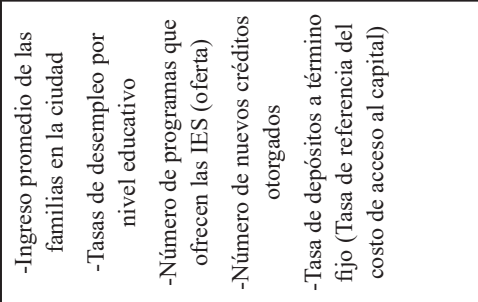 \\
\hline 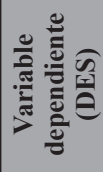 & 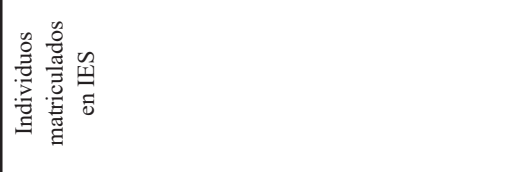 & 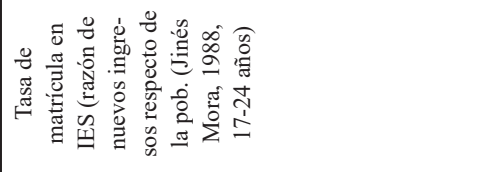 \\
\hline 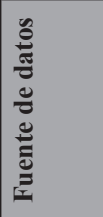 & 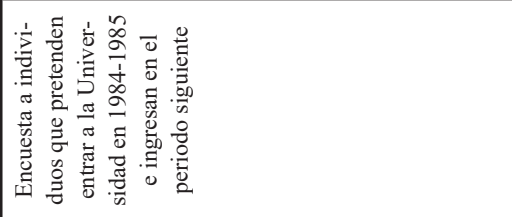 & 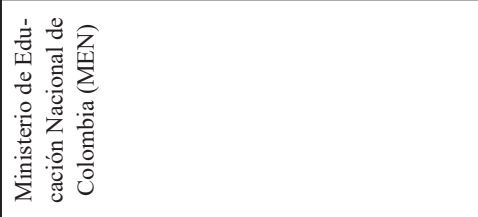 \\
\hline 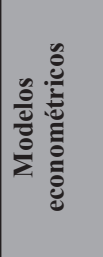 & 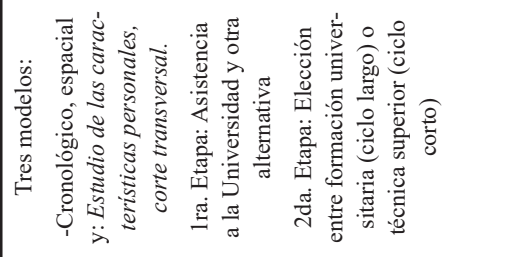 & 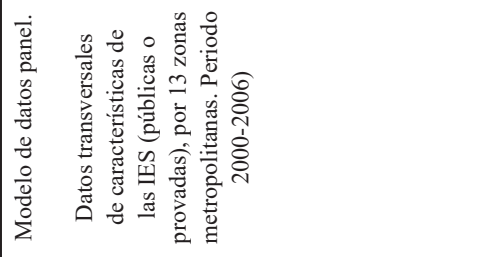 \\
\hline$\stackrel{\grave{g}}{\mathrm{e}}$ & 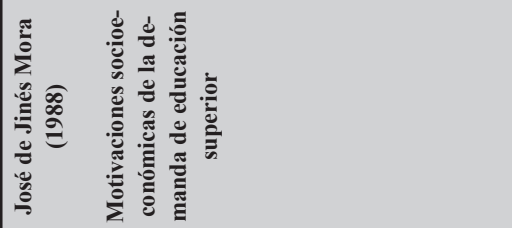 & 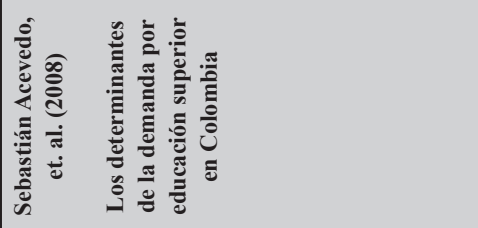 \\
\hline
\end{tabular}




\begin{tabular}{|c|c|}
\hline 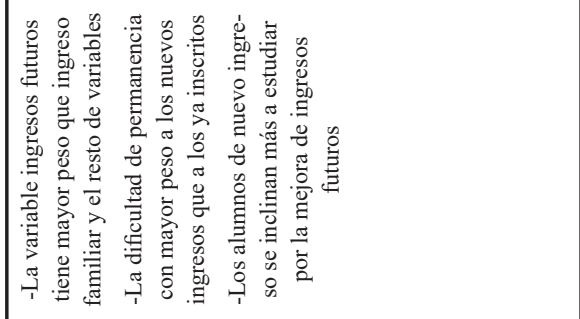 & 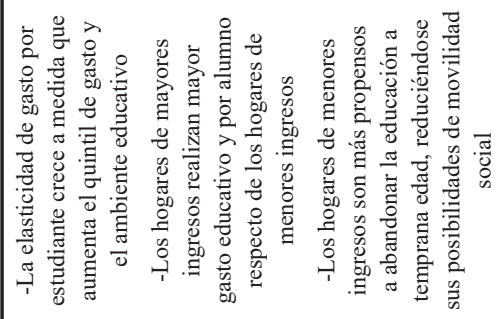 \\
\hline 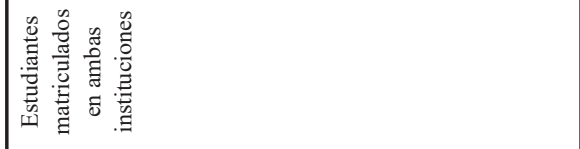 & \\
\hline 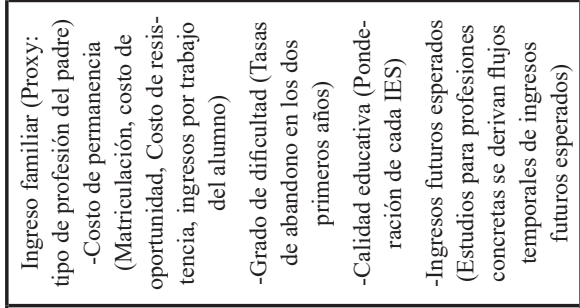 & 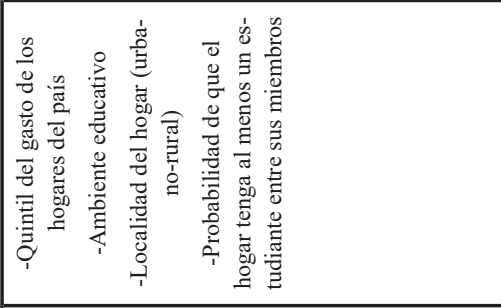 \\
\hline 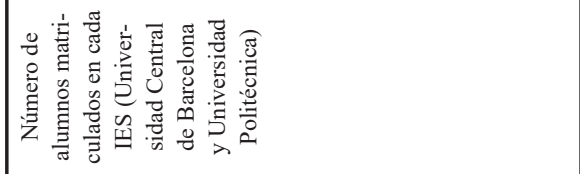 & 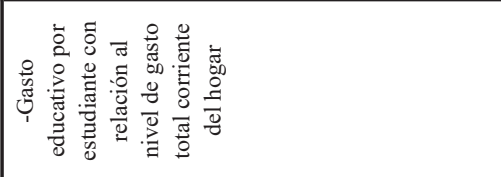 \\
\hline 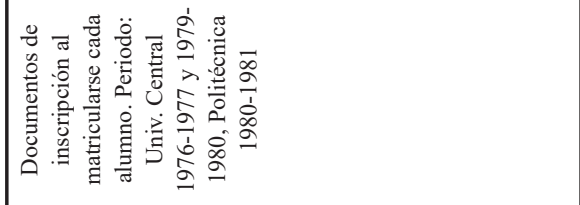 & 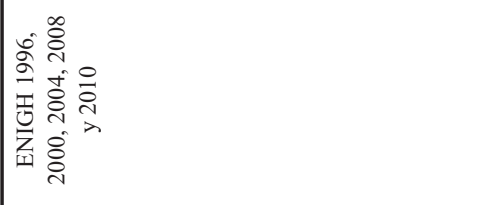 \\
\hline 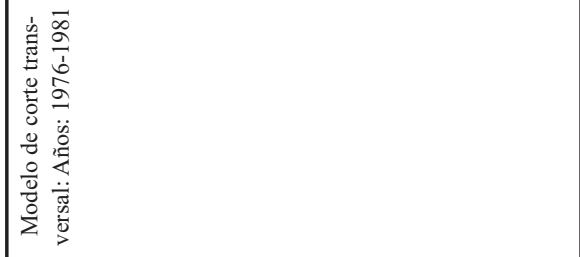 & 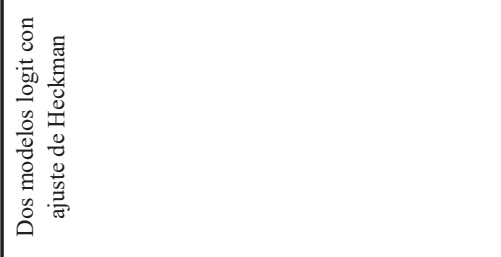 \\
\hline 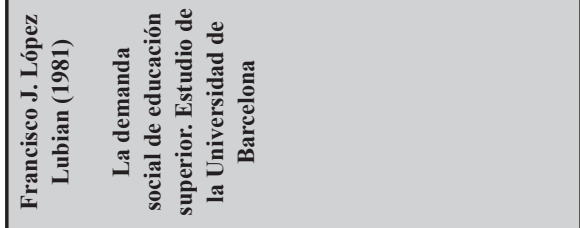 & 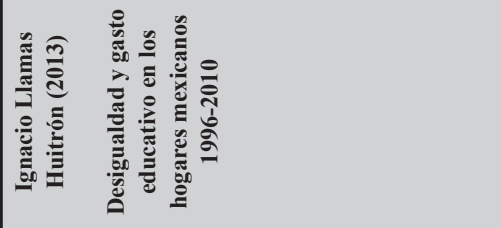 \\
\hline
\end{tabular}


